\title{
STUDY OF MORPHOLOGICAL CHANGES AND SUSTAINABLE DEVELOPMENT ON THE SOUTHERN COASTS OF THE CASPIAN SEA USING REMOTE SENSING AND GIS
}

\author{
SEYED AHMAD NESHAEI ${ }^{1}$, PAYAM ALEMI SAFAVAL ${ }^{2}$, \\ MIR MASOUD KHEIRKHAH ZARKESH ${ }^{2} \&$ PARASTOO KARIMI $^{2}$ \\ ${ }^{1}$ Department of Civil Engineering, University of Guilan, Iran \\ ${ }^{2}$ Department of Remote Sensing and GIS, Islamic Azad University, Iran
}

\begin{abstract}
Coastal areas are continuously subject to global changing and the interaction of land and sea resulting in the short- and long-term transformation. Study of beach morphology has been one of the most important issues in coastal engineering research projects. Managing and controlling the shoreline changes and behavior are essential for marine projects and integrated coastal zone management policy in such environment. In the present study, based on the available data of Guilan province region, an analysis of the coastal zone behavior is made. Based on extensive research, the bed level changes and submerged area due to a rise in sea level at different locations inside the study area are estimated and compared with those obtained from the satellite images based on remote sensing indicating a good consistency. The results of survey are presented graphically and changes in shorelines are estimated using sensors' ETM+ and OLI images from 2002 to 2013, which can be used for site selection and design of marine structures and establishing a data base for the sustainable development of the coastal zone in the study region. Laplacian filter is applied to satellite images to establish the shoreline and to clarify the effect of ports and coastal structures constructed in the study region on beach and shoreline morphological changes. This study is a combination of remote sensing and GIS methods with field observations on the ground. The innovation of this work is using Laplacian filters for shoreline detection and estimation of the sediment deposition area by calculating the distance between the observed shorelines. This will lead us to the better understanding of the effect of coastal structures on the beach morphology using satellite images. The results show the remarkable changes occurred in the shoreline due to the environmental and human-based effects during the study period.
\end{abstract}

Keywords: Caspian Sea, change detection, coastline, GIS, remote sensing, sediment area.

\section{INTRODUCTION}

The Caspian Sea is the largest enclosed body of water in the Earth by a surface area of 372000 square kilometers and a volume of 78200 cubic kilometers. Its latitude and longitude are $40^{\circ}$ $0^{\prime} 0^{\prime \prime}$ and $51^{\circ} 0^{\prime} 0^{\prime \prime}$, respectively. The lake accounts for $40-44$ percent of the total lacustrine waters of the world. It has a maximum depth of about 1025 meters. Guilan province is located in the southern coast of Caspian Sea where the existence of the Sefidroud delta and Bandar Anzali port make this area very important (Fig. 1). The coastal zone in this area is mainly formed and covered by sand, which is the main reason for rapid changes in coastal morphology [1].

Coastal areas such as barrier islands, beaches, and wetlands are highly sensitive to sealevel changes. Rising seas will intensify coastal flooding and increase the erosion of beaches, bluffs, and wetlands, as well as threaten jetties, piers, seawalls, harbors, and waterfront property. In addition to immediate impacts due to anthropogenic activities, global warming and sea-level rise will have serious long-term consequences for coastal ecosystems, such as wetlands and coral reefs. 


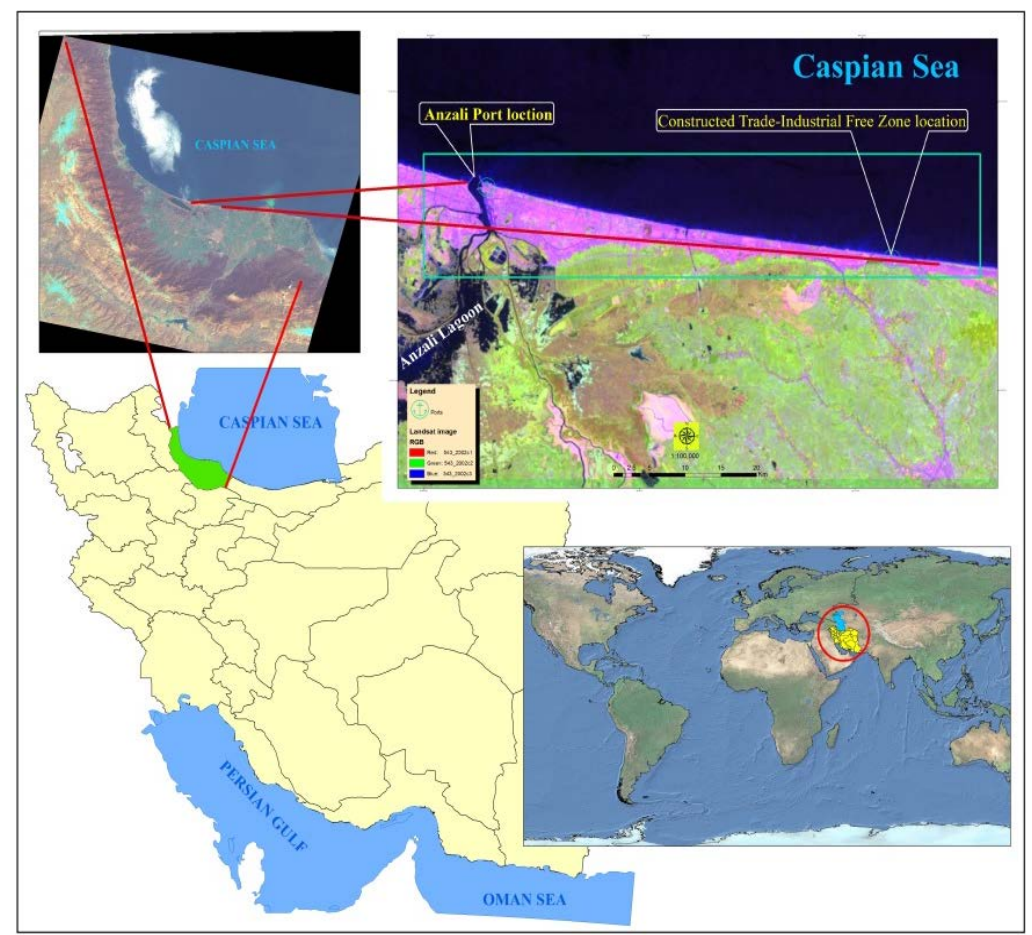

Figure 1: Location of the study area.

The effects of sea level rise on coastal morphology covering the current study area have been investigated by different researches [2]. The results of the measurements on the southern coastlines of the Caspian Sea especially the Anzali region which located in Guilan province shows a parabolic behavior of sandy coasts in this region which is compatible with the Dean's equilibrium profile [3]. Some of the factors which cause the sea level rise are atmospheric rain fall, climate changes and tectonic movements [4].

The dramatic sea level rise of the Caspian Sea (about 2.25 meters since 1978) has caused serious concern to all five surrounding countries. The assessment of the role of various factors in sea level changes is essential to be able to develop predictive models [5]. Due to the rapid Caspian Sea level changes which has been observed during the last century, it is absolutely essential to provide a data-base for each coastal zone. One of the most important zones of Caspian coastlines is its south line which borders the north of Iran.

\section{DATA AND MODELLING}

Prediction of coastal morphological changes as sea level fluctuates is not easy due to a number of difficulties. On one hand, predictive models are not being reliably generated due to a lack of knowledge of the interaction between coasts and energy sources. On the other hand, a model which is developed to forecast the behavior of a particular coast cannot be applied to another because natural processes depend on coastal features which differ from one coast to another. Fig. 2 shows the Bruun's first theory about beach profile geometry [6]. Later in 1962 Bruun proposed that the equilibrium beach profile does not change in response to sea level variations (Bruun Rule). In his view, in the case of sea level changes only a given 
volume of sand will move from the upper part of the profile and this volume of sand will lie over the lower part of the profile; the accumulated volume is equal to the eroded volume.

Based on the Bruun Rule, since the shore-normal geometry of beaches remains unchanged under sea level rise conditions the amount of shoreline retreat can be calculated if the amplitude of sea level rise and the form of the original profile are known. This is a geometric model and can be applied if assumed geometric rules are valid.

Fig. 3 shows the Caspian Sea level rise history for a period of 64 years based on the report from the Ports and Marine Administrations of Guilan province, 2015 [1].

Recently, the Integrated coastal zone management (ICZM) procedure is carried out in the southern coasts of the Caspian Sea [7]. The main aim of this research is to identify the coastal problems and minimizing the impacts of different affecting factors on the coastal environment. The important factors affecting the shoreline changes can be categorized into the two main groups of natural-based and human-based elements.

Coastal zone monitoring is an important task in sustainable development and environmental protection. For coastal zone monitoring, coastline extraction in various times is a fundamental work. Coastline is one of the most important linear features on the earth's surface, which has a dynamic nature. Remote sensing plays an important role for spatial data acquisition in coastal area from economical perspective [8].

With the wide variety of remote sensing systems available, choosing the proper data source for observing land cover and coastal waters can be challenging. Characteristics often used to describe and compare these analogue and digital systems are grouped into four different types of resolution: spatial, spectral, radiometric, and temporal. Spatial resolution

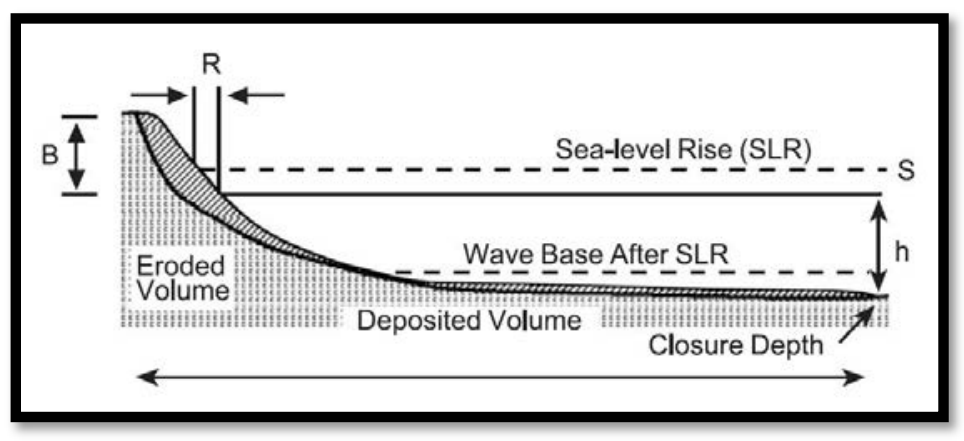

Figure 2: Shoreline erosion under rising sea level conditions, the Bruun Rule [6]

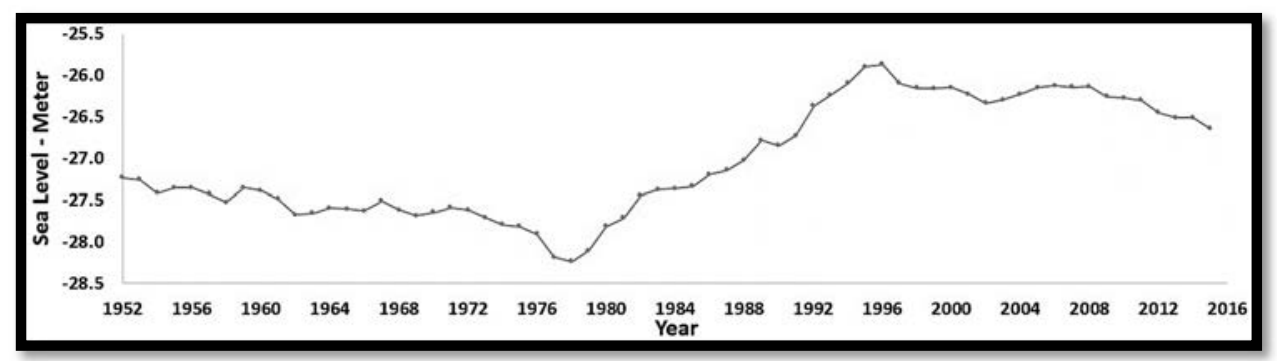

Figure 3: 60 years of the Caspian Sea level changes according to the high sea level [1]. 
is a measure of sharpness or fineness of spatial detail. It determines the smallest object that can be resolved by the sensor, or the area on the ground represented by each picture element (pixel). For digital imagery, spatial resolution corresponds to the pixel size.

In the present work, the emphasis is mainly focused on the two factors which are believed to have the remarkable effect on coastal changes named as current pattern and sea level global changing; and construction of ports or coastal structures which are the representative of the two main mentioned groups, respectively. Remote sensing is used to detect the changes and help us to manage and predict the behavior of the selected coasts. Fig. 4 shows some samples of the selected targets in the study area. As can be seen, the coasts are mainly made of the typical sand and the intrusion of sea water inside the shorelines is clear. Also, Fig. 5 shows the typical coasts of the Anzali trade industrial free zone which clearly indicates the effect of sea level drawdown and the resulting sedimentation in the shore.

\section{STUDY APPROACH}

Coastal landscapes are being transformed as a consequence of the increasing demand for urban infrastructure to sustain commercial, residential and tourist activities. A variety of manmade structures, such as breakwaters, jetties and seawalls have thus become ubiquitous features of intertidal and shallow subtidal habitats. This transformation will accelerate in

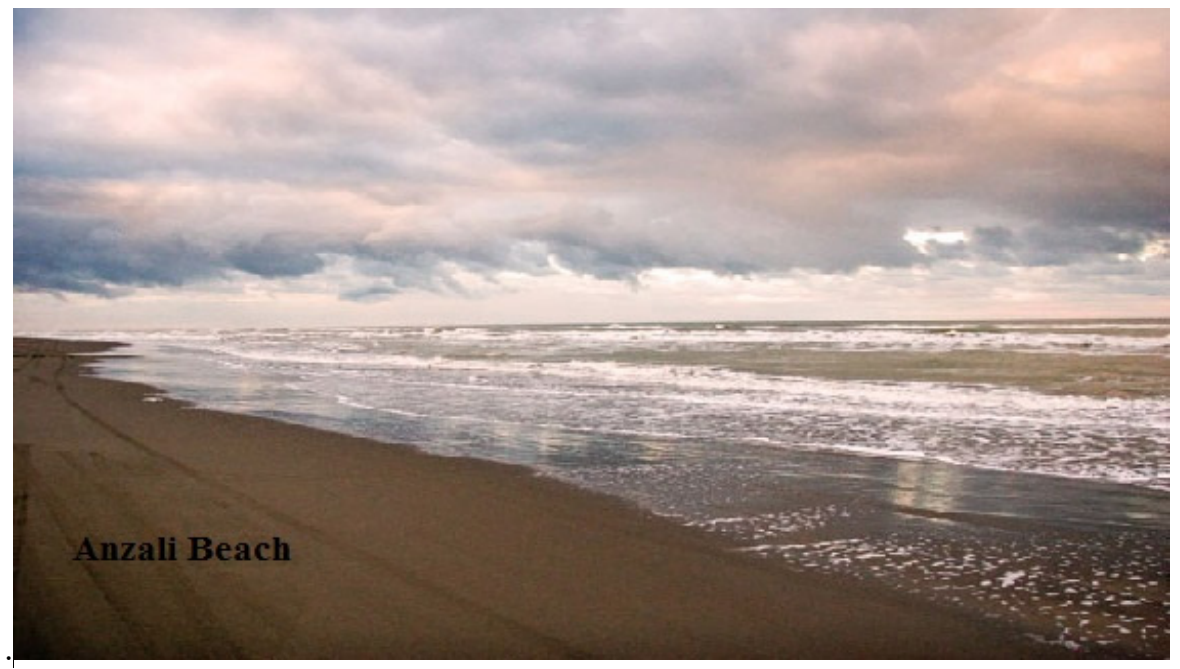

Figure 4: Samples of the coasts which are located in the southern Caspian Sea.
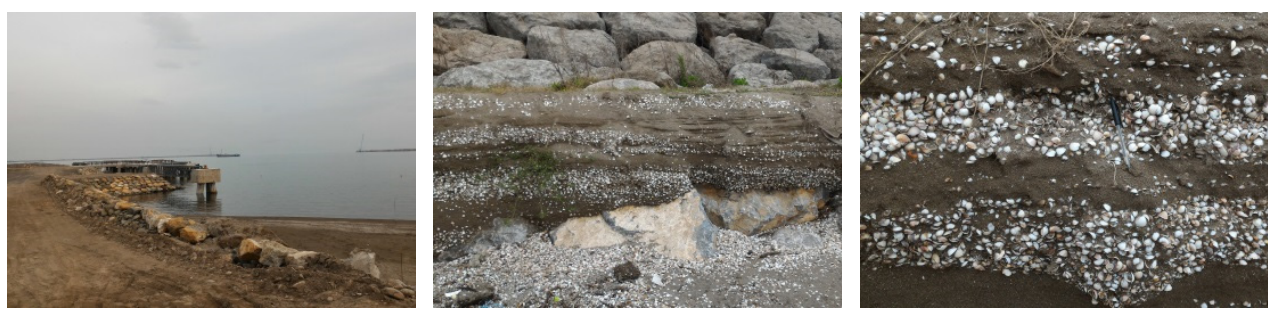

Figure 5: Typical coasts of the Constructed Trade-Industrial Free Zone. 
response to the exponential growth of human populations and to global changes, such as sealevel rise and increased frequency of extreme meteorological events (e.g. storms). Here, we provide a critical overview of the major ecological effects of increasing infrastructure to marine habitats, we identify future research directions for advancing our understanding of marine urban ecosystems such as Anzali region in our study and we highlight how alternative management options might mitigate their impacts.

This study, by means of remote measurement and Landsat +ETM8 satellite images, attempts to analyze the southern coast of Caspian Sea in an eleven years period between 2002 and 2013. The length of the studied region is 20 kilometers which is extended, from north of Anzali lagoon to Constructed Trade-Industrial Free Zone. The importance of this region is due to the existence of Anzali lagoon and also existence of the largest port in southern coast of Caspian Sea and Caspian Trade-Industrial Free Zone in the studied region.

Following enhancement of images using Laplacian filter in the periods of 2002 to 2013, the shorelines have been plotted and then the distance between these two lines which shows the morphological changes were measured and the changes in shorelines have been achieved (Fig. 6). Finally, using the polygon of the shorelines, the area of sedimentation during the mentioned period has been estimated.

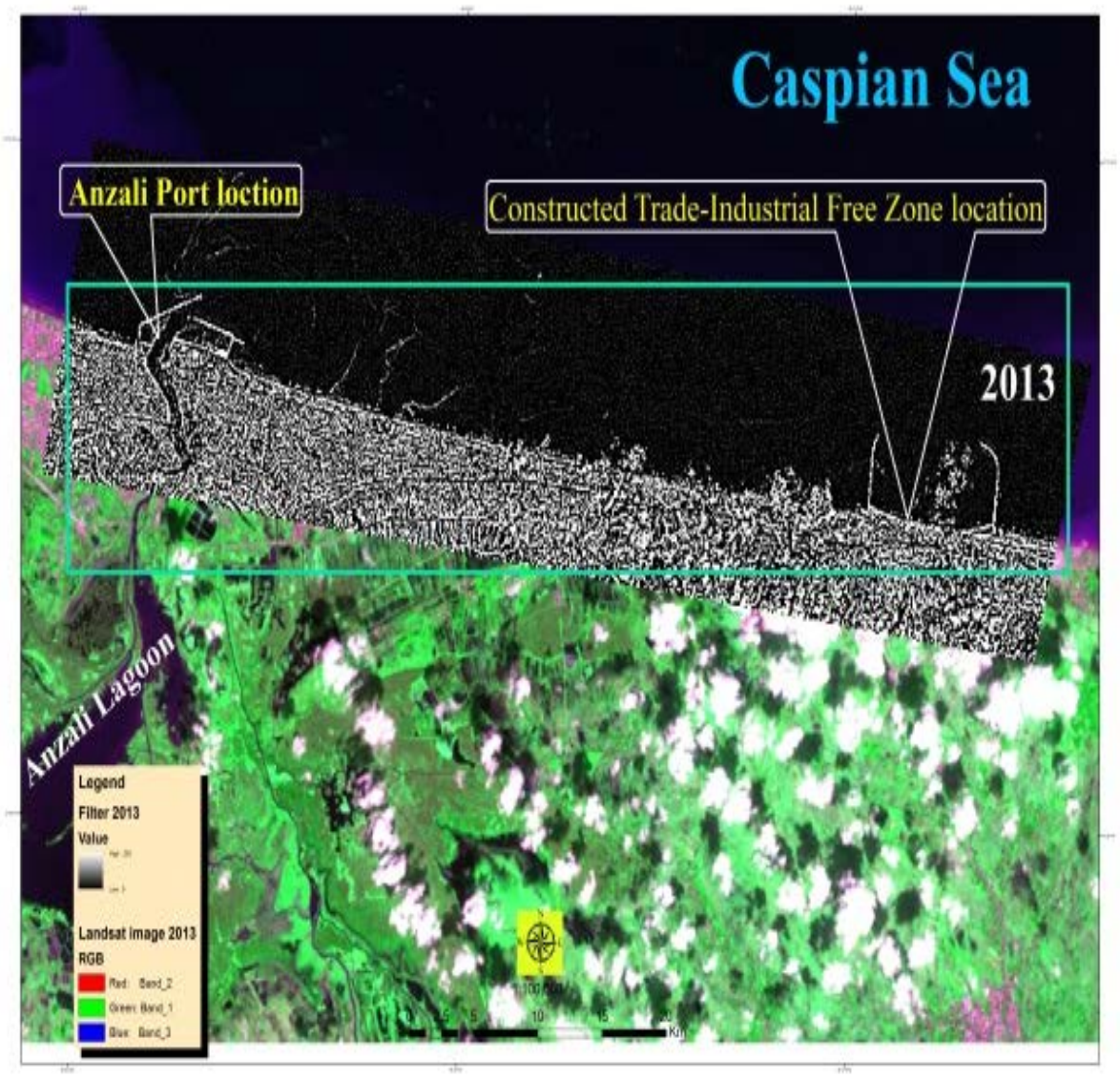

Figure 6: Shoreline configuration using Laplacian filter in 2013. 
The Remote Sensing and GIS studies of Caspian Sea's coastline provided a classic study, input, process, and output of information and maps. The aims of this study were to determine the position of erosion and sediment in coastline and the natural factors in the photography of two periods, and to determine the location of sedimentation and erosion. Deposition of sediments in the region, due to environmental conditions, result in different geomorphological forms such as ponds and coastal swamps [9].

\section{RESULTS AND DISCUSSIONS}

The summary of investigation in the coastal areas of Guilan Province shows deposit morphology bars. Based on field research and the conclusions derived from it, changes occurring in the units of erosion result from various processes like coastal erosion, sedimentation, the creation of new units of erosion, and human activities in the field of building ports, roads, cities, and coming into being of small ponds behind sand dunes and changes in the coastal morphology [10]. Fig. 7 shows the location of port structures which have effect on morphological changes of the study area by comparing their situations before and after the construction.

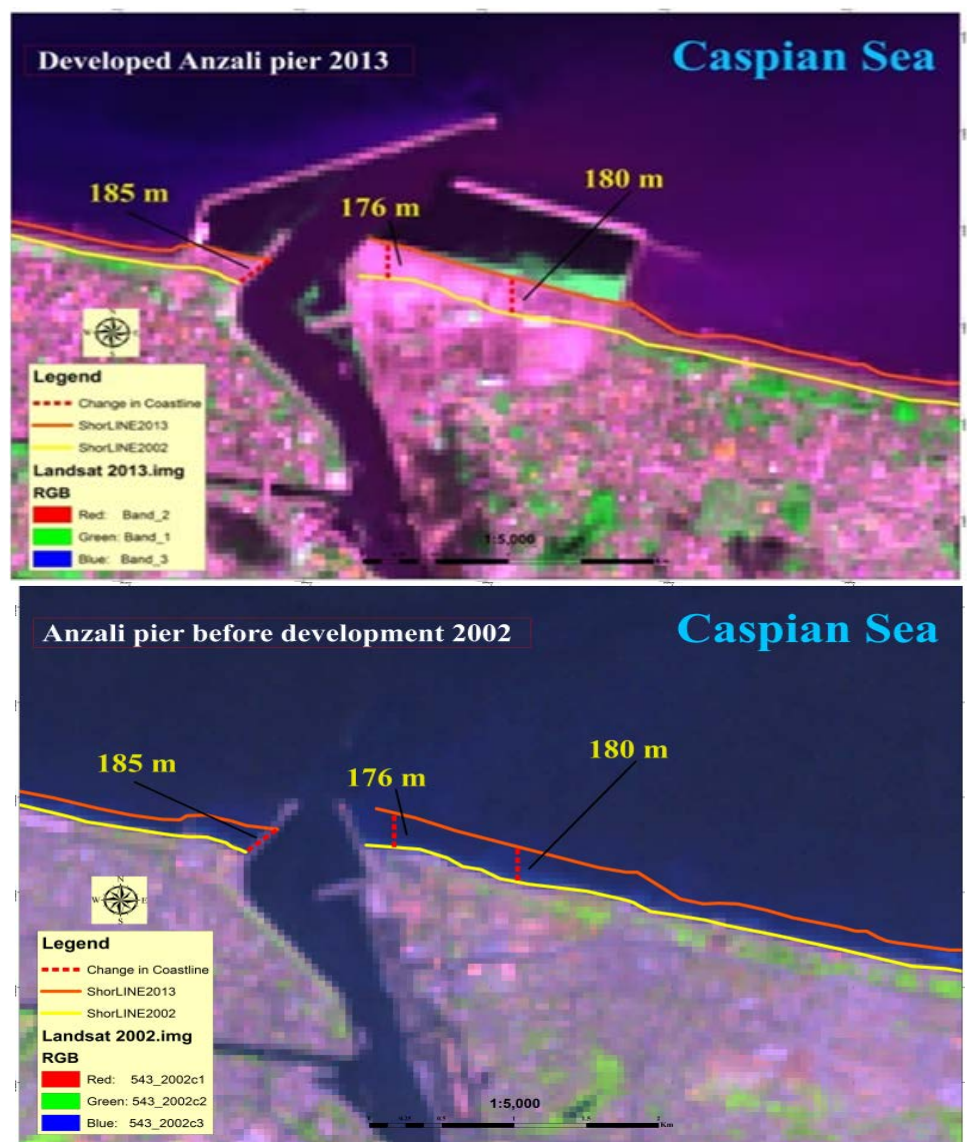

Figure 7: Comparison of the shoreline configuration between the two periods due to the port construction. The yellow line shows the location of shoreline before construction. 
Fig. 8 shows the magnitude of morphological changes in the shorelines as a result of the satellite image data analyses based on created maps in the present study.

A comparison between the two coastal lines in the images show that in a period of eleven years, the shoreline has made a change of 52 to 185 meters with respect to the coast's morphology. A remarkable amount of the changes has taken place surrounding the expanded Anzali port and the newly started port of Caspian Trade-Industrial Free Zone (Fig. 7).

It is clear that the morphological changes are dominant in the coasts which are located near the coastal structures [11]. The total area of the deposited sediments is 161.6 ha including 52 to 185 meter of intrusion zones (Fig. 9). These observations are consistent with those reported by different researchers [12]-[14]. In their study, the amount of sediments

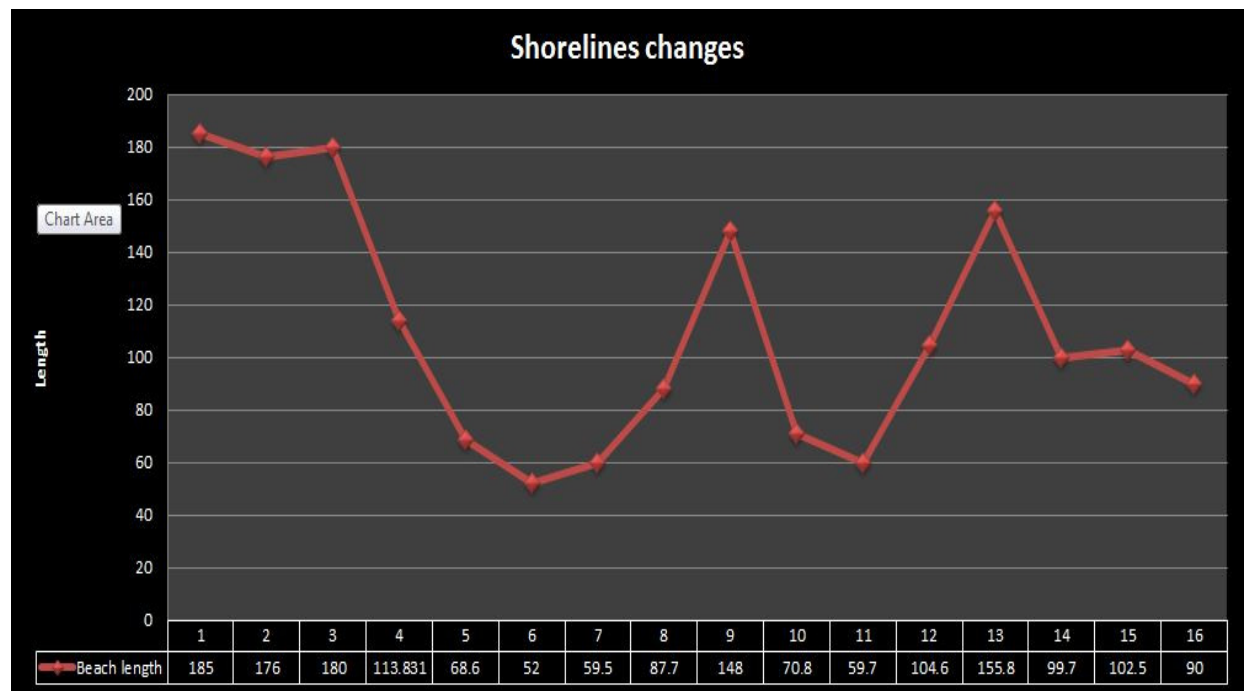

Figure 8: Magnitude of changes in the shorelines of the study area.

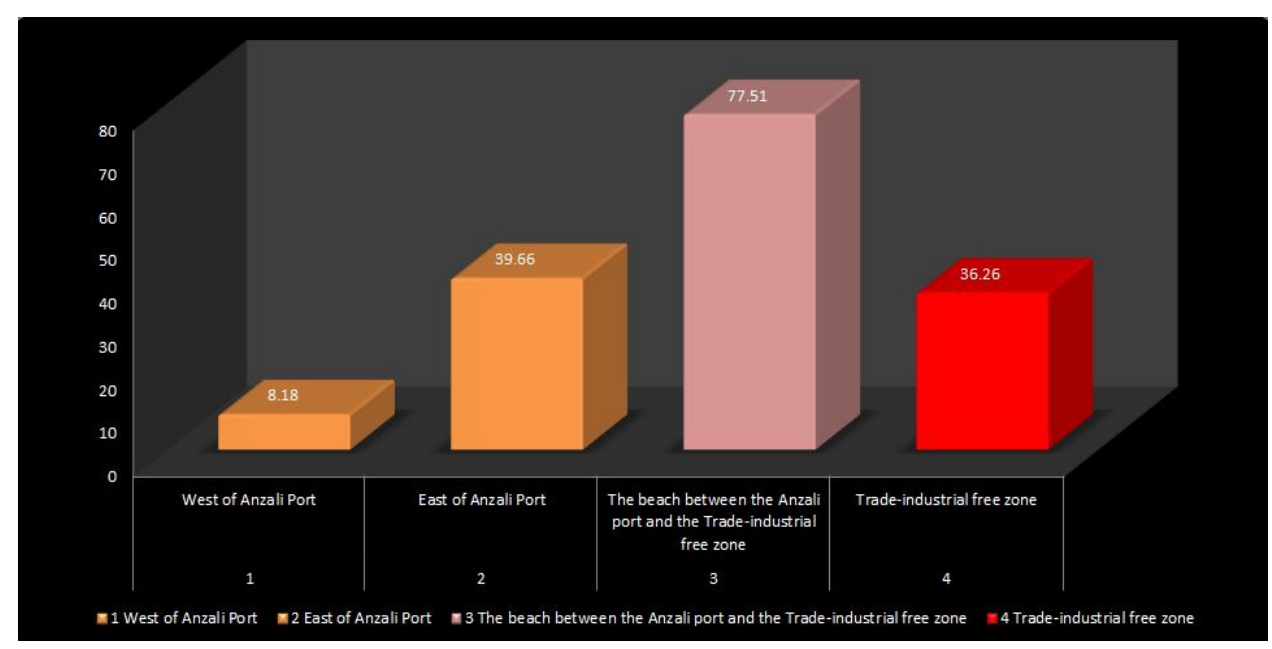

Figure 9: Magnitude of deposition in the shorelines of the study area (ha). 
deposited on the back face of a groin located in the study area was measured and compared with the empirical and numerical models leading to this result that the construction of protective structures has a considerable effect on coastal morphology. The reason that the majority of changes in the shorelines of the accretional type could be attributed to the resignation of the sea water level during the last decade [15], [16].

\section{CONCLUSIONS}

This study is a combination of remote sensing and GIS methods with field observations. The innovation of this work is using Laplacian filter for shoreline detection and estimation of the sediment deposition area by calculating the distance between the observed shorelines which can be used as a basis for any projects related to the sustainable development in the study area.

Assessment of the morphological changes detected during an eleven-year period using remote sensing and GIS in the study area, clearly shows that the combination of natural and human-based factors has caused remarkable changes in the shoreline and coastal patterns particularly in the vicinity of ports and man-made structures.

Construction of any port or marine structure in the studied region can have a remarkable effect on coast morphology by means of changing the sediment transportation pattern. This will in turn, change the morphology of coasts by alternate erosion and accretion processes in combination of the periodical water level fluctuations. Finally, the outputs of images processing using remote sensing and GIS in the study region clearly confirm the results of reported documents indicating the effect of water level fluctuation on coastal morphology.

It is evident that the coastal area in the southern part of the Caspian Sea, particularly in the study region, has faced a remarkable change during the period of measurements and the results of remote sensing and GIS monitoring clearly confirm and detect this observation.

To construct any port or marine structures along the coastal area in the study region, it is important to track the environmental impact of such man-made structure and its interaction with the sea-level fluctuations into account. Results of this work can be of great help to optimize the location of the coastal structures using remote sensing and GIS for site selection in such a way that the minimum destructive impacts occur in the nature.

\section{REFERENCES}

[1] Firoozfar, A., Bromhead, E.N., Dykes, A.P. \& Lashteh Neshaei, M.A., Southern Caspian Sea coasts, morphology, sediment characteristics, and sea level change. The 27th Annual International Conference Soil, Sediments, Water and Energy, October 17-20, MA, USA, 2011.

[2] Short, A.D., Handbook of Beach and Shore Face Morphodynamics, John Wiley, 1999.

[3] Dean, R.G., Equilibrium beach profiles, characteristics and applications. Journal of Coastal Research, CERF, 7(1), pp. 53-83, 1991.

[4] Nairn, R.B. \& Southgate, H.N., Deterministic profile modelling of nearshore processes. Coastal Eng., 19, pp. 57-96, 1993.

[5] Haghani, S. \& Leroy. S., Differential impact of long-shore currents on coastal geomorphology development in the context of rapid sea level changes: The case of the Old Sefidrud (Caspian Sea). Quaternary International, 408, pp. 78-92, 2016.

[6] Bruun, P., Sea-level rise as a cause of shore erosion. Journal of the Waterways and Harbors Division, 88(1), pp. 117-132, 1962.

[7] Pak, A. \& Farajzadeh, M., Iran's integrated coastal management plan: Persian Gulf, Oman Sea, and Southern Caspian Sea coastlines. Ocean \& Coastal Management, 50, pp. 754-773, 2007. 
[8] Alesheikh, A.A., Ghorbanali, A. \& Nouri, N., Coastline change detection using remote sensing. Int. J. Environ. Sci. Tech., 4(1), pp. 61-66, 2007.

[9] Bird, Coastal Geomorphology an Introduction, Wiley and Sons Ltd., 322 pp., 2000.

[10] Neshaei, M.A.L., Veiskarami, M. \& Nadimy, S., Computation of shoreline change: A transient cross-shore sediment transport approach. International Journal of Physical Sciences, 6(24), pp. 5822-5830, 2011.

[11] Hoque, M.A., Asano, T. \& Lashteh Neshaei, M.A., Effect of reflective structures on undertow distribution. Proceedings of the Fourth International Symposium Waves 2001, California, USA, 2, pp. 1042-1051, 2001.

[12] Afsoos Biria, H., Lashteh Neshaei, M.A., Ghabraei, A. \& Mehrdad, M.A., Investigation of sediment transport pattern and beach morphology in the vicinity of submerged groyne (case study: Dahane Sar Sefidroud). Front. Struct. Civ. Eng., 2014. DOI: $10.1007 / \mathrm{s} 11709-014-0275-5$.

[13] Winarso, G. \& Budhiman, S., The potential application of remote sensing data for coastal study. Proc. 22nd Asian Conference on Remote Sensing, Singapore, 2011.

[14] Khoshraftar, R., Geomorphology of Sefidroud River new delta in Southern Caspian Seacoast during 80 years ago. Proceedings of the 5th WSEAS International Conference on Environment, Ecosystems and Development, Venice, Italy, November 20-22, 2006.

[15] Haghani, S., Leroy, S., Wesselingh. F. \& Rose, N., Rapid evolution of coastal lagoons in response to human interference under rapid sea level change: A south Caspian Sea case study. Quaternary International, 408(93e112), 2016.

[16] Khoshravan, H. \& Mammadov, R., The hydromorphology of the Caspian Sea. International Journal of Marine Science, 7(3), pp. 19-30, 2017. 